\title{
The first evidence for Late Pleistocene hominin populations on the southern Caspian Sea coast
}

\author{
Hamed Vahdati Nasab ${ }^{1, *}$, Kourosh Roustaei ${ }^{2}$, \\ Mohammad Ghamari Fatideh ${ }^{3}$, Fatemeh Shojaeefar ${ }^{4}$ \\ $\&$ Milad Hashemi Sarvandi ${ }^{1}$
}

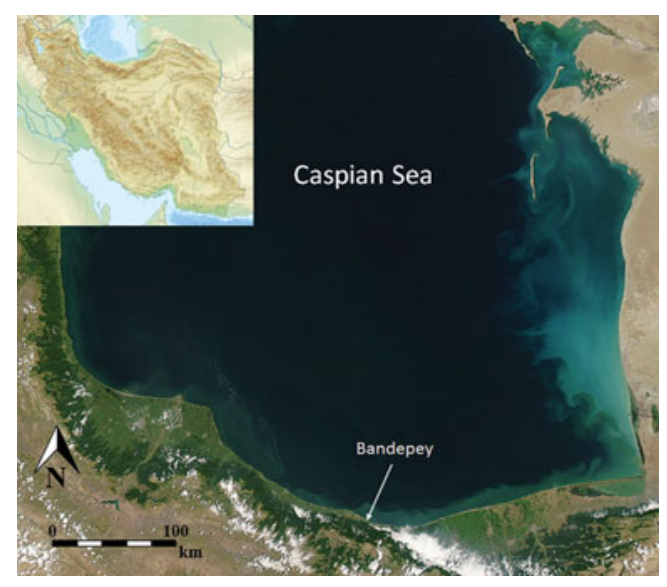

Figure 1. Location of the Bandepey Palaeolithic site near the south coast of the Caspian Sea.
The southern shore of the Caspian Sea is well known for its great potential in relation to sites of Mesolithic date (e.g. Coon 1951; Jayez \& Vahdati Nasab 2016). Situated between two major geographic barriers-the Alborz Mountains to the south, and the Caspian Sea to the north-this area has been considered one of the major hominin dispersal corridors during the Pleistocene-Holocene transition (Vahdati Nasab et al. 2013). Furthermore, the relatively stable and mild climatic conditions, vast and lush temperate forests, and abundance of fauna and water resources have all made this region an attractive niche for human settlement.

During July 2016, one of the authors (FS) discovered, by chance, a number of stone artefacts in the mountains $5 \mathrm{~km}$ east of the city of Nowshahr in an area known locally as Bandepey (Figure 1). The area lies at an elevation of $400-700 \mathrm{~m}$ on the northern flank of an anticline overlooking the Caspian Sea. Following the initial observation, a permit was issued by the Iranian Center for Archaeological Research to survey in the area.

An intensive pedestrian survey, with a crew of five members, walked in cardinal directions from the original finds spot to establish the extent of visible lithic materials. As the area lies within temperate forest, the ground surface was mostly covered by plants; lithics were

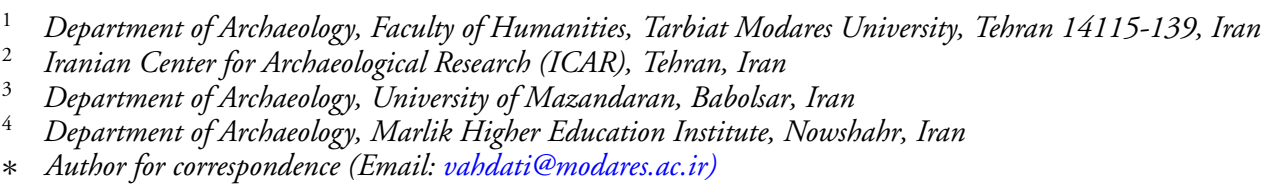




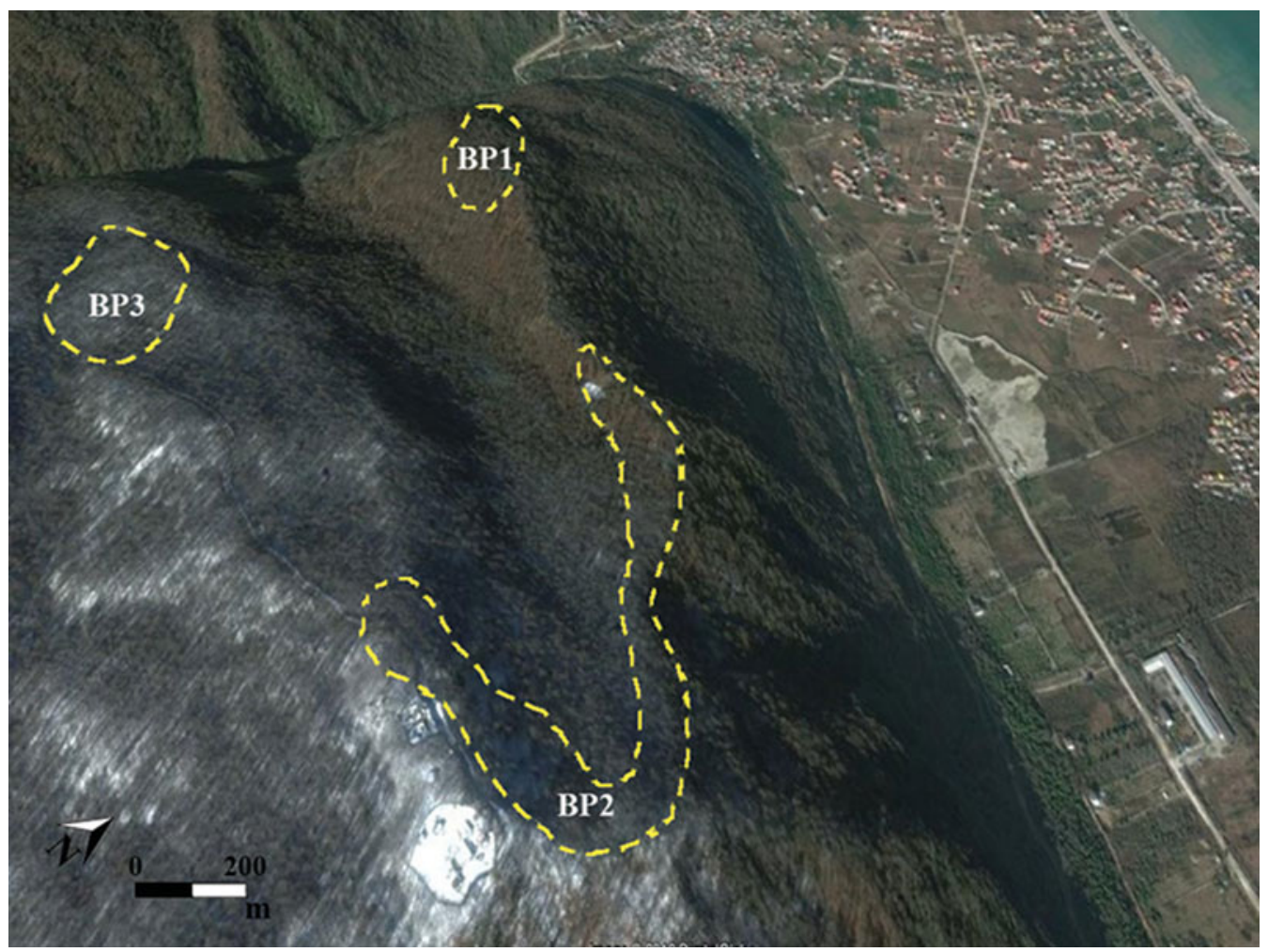

Figure 2. Extent of the Bandepey site (courtesy of Google Earth with some modifications).

therefore mainly observable in patches without vegetation, such as on the slopes affected by vehicles' tracks, or in the sections of small gullies created by seasonal rain. Our brief survey

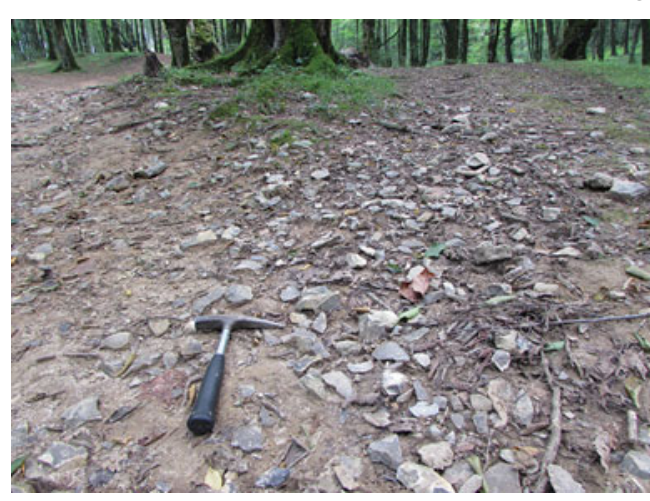

Figure 3. Density of artefacts on the surface. located lithic concentrations of various sizes extending across an area of beyond 200ha (Figure 2); the full extent of the lithic scatters is yet to be identified and further work might significantly extend the area of archaeological interest. Levels of lithic density were recorded where visibility was good (Figure 3). One sample area of 1 $\times 1 \mathrm{~m}$ produced 234 chipped stone pieces; extrapolated across the whole area, this would suggest the presence of hundreds of thousands of pieces across the wider site. Grab samples were collected at five different spots, and a $10 \times 10 \mathrm{~m}$ square was subject to the complete collection of all tools, debitage, debris and cores.

Our initial results suggested the presence of at least three major concentrations (BP1-3 in Figure 2) in the area. Further work, however, suggests that all of these scatters should be (C) Antiquity Publications Ltd, 2017 


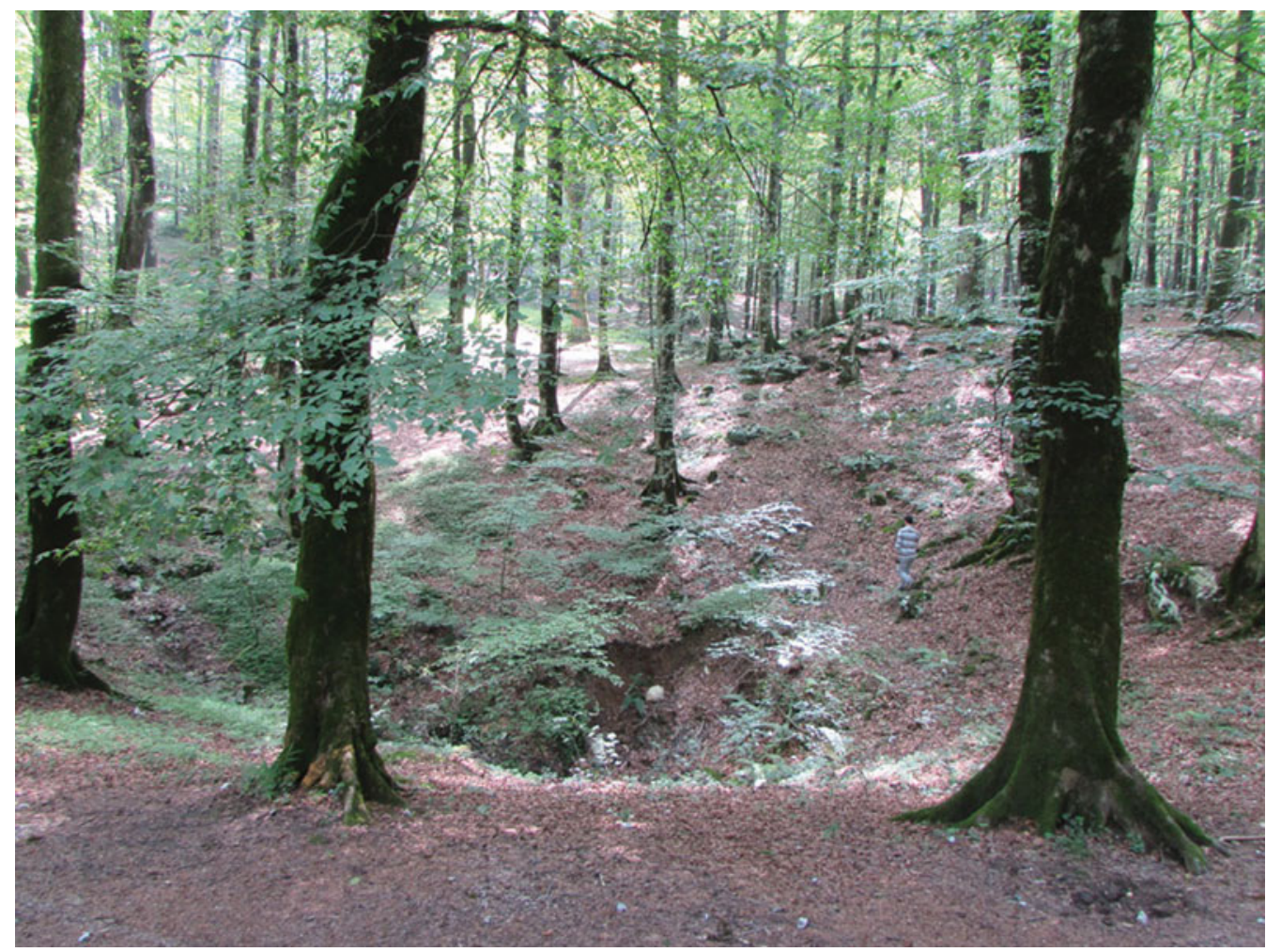

Figure 4. Example of a sinkhole.

considered as components of a single larger site, which has been disturbed by natural and human activities such as erosion and road building. Aside from the close proximity of the

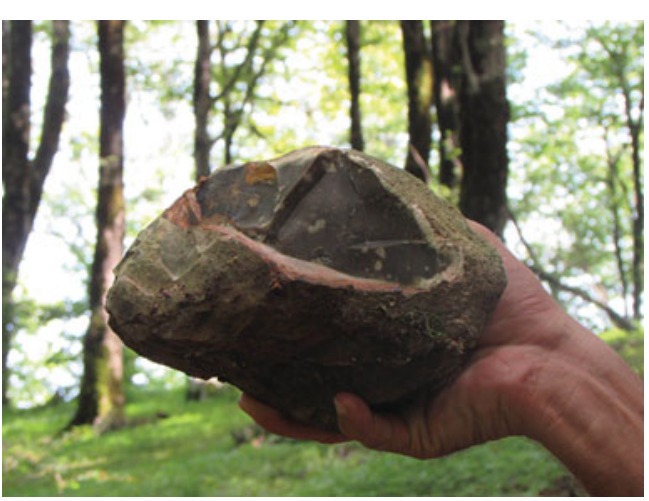

Figure 5. Example of a broken piece of natural rock with silicified parts inside. three scatters, there is significant homogeneity in the raw materials and lithic industries employed.

The study area forms part of the central Alborz Mountains that are comprised mainly of sedimentary formations such as limestone, sandstone, shale and conglomerates. The surface lithic scatters that we have identified are closely associated with Orbitolina-rich limestone bed rock: a karstic formation associated with numerous sinkholes of various sizes (Figure 4). Our preliminary study of the Bandepey finds suggests the use of a highly silicified greyish-brown limestone for the production of chipped stone artefacts. Evidence of such silicification exists on some of the natural rocks on the surface, which were tested using a geology hammer (Figure 5).

(C) Antiquity Publications Ltd, 2017 

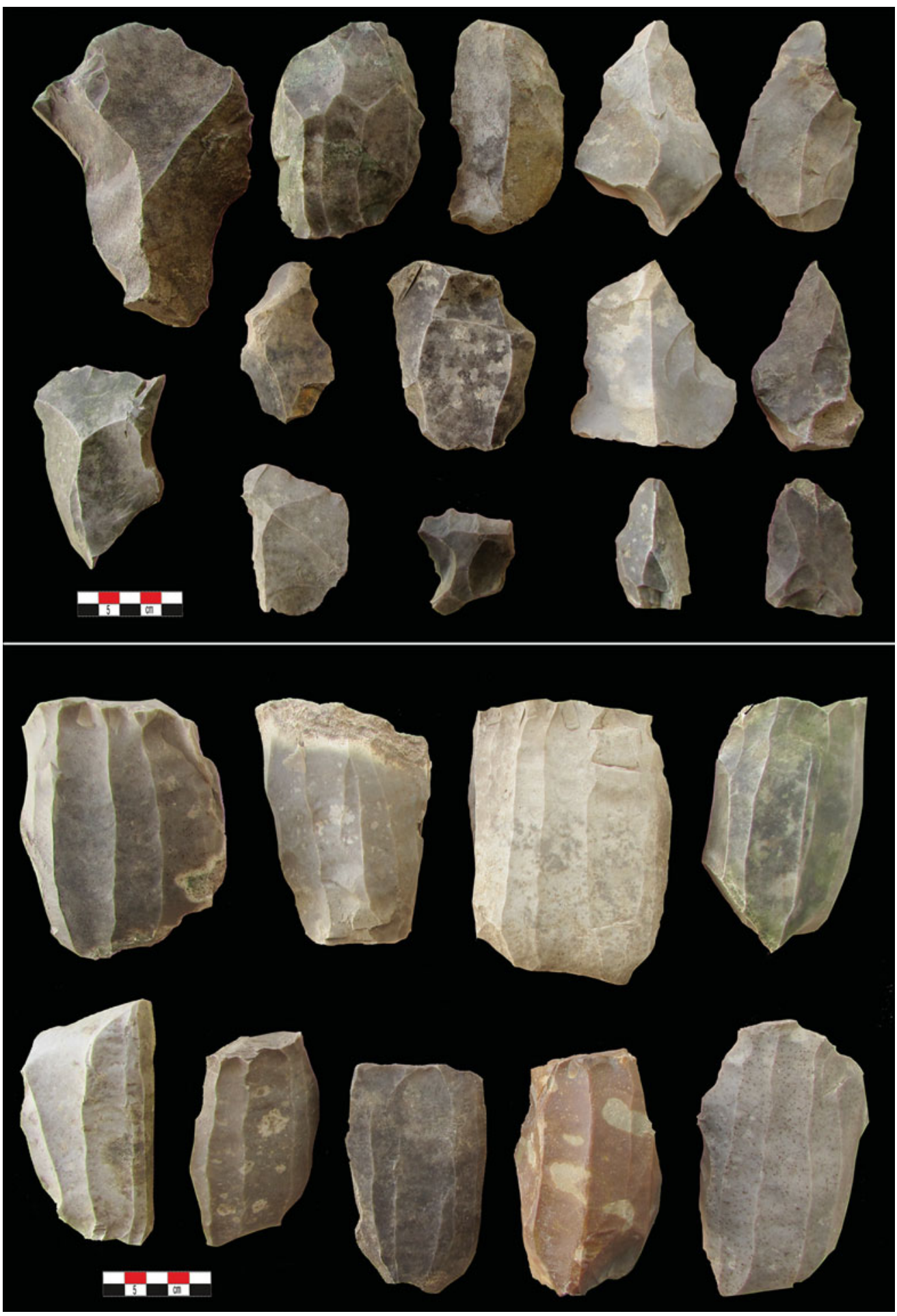

Figure 6. Examples of some of the collected artefacts in Bandepey: top) Levallois pieces; bottom) tongue-shaped blade cores. (C) Antiquity Publications Ltd, 2017 
Preliminary examination of the collected artefacts indicates an abundance of chipped stones with no signs of secondary modifications (debitage). The size of the artefacts is relatively large ( $>150 \mathrm{~mm}$ in length), with large core/core fragments dispersed across the site, supporting the suggestion of the on-site availability of the raw materials. Among tools, notched pieces/denticulates are the most frequent types (Figure 6). Almost all of the collected pieces from across the surveyed area were made using the Levallois technique. Overall, based on both tool typology and lithic technology, it is possible to propose a Middle Palaeolithic date for all but one of the lithic scatters. The only exception seems to be a small natural mound from where a series of diagnostic elements of Upper Palaeolithic industries, such as tongue-shaped blade cores (Figure 6), were collected. Bandepey is therefore the first Palaeolithic site to be reported from the central Alborz Mountains. It should also be noted that no material characterised by elements of later periods, such as blades or bladelets, has so far been identified at the site.

Although the study of the Bandepey Palaeolithic site is still in its preliminary stages, its great size and the large number of the artefacts already documented make it a unique case within Iranian Palaeolithic archaeology.

\section{Acknowledgements}

We would like to thank the Research Center for Cultural Heritage and Tourism for granting us the permit to conduct the survey at the site. We also would like to thank Mehdi Mousavi Kouhpar and Kia at the Marlik Higher Education Institute for providing accommodation for the crew. We would further like to thank Delawar Bozorgnia, Director of the Cultural Heritage Office in Mazandaran province, and also Sahar Sheykhi for her help.

\section{References}

Coon, C.S. 1951. Cave explorations in Iran 1949. Philadelphia: The University Museum, University of Pennsylvania.

Jayez, M. \& H. Vahdati Nasab. 2016. A separation: Caspian Mesolithic vs Trialetian lithic industry (a research on excavated site of Komishan, south-east of Caspian Sea). Paléorient 42: 81-100.
Vahdati Nasab, H., G.A. Clark \& S. Torkamandi. 2013. Late Pleistocene dispersal corridors across the Iranian Plateau: a case study from Mirak, a Middle Paleolithic site on the northern edge of the Iranian Central Desert (Dasht-e Kavir). Quaternary International 300: 267-81. http://dx.doi.org/10.1016/j.quaint.2012.11.028 